\title{
Palinuro y su fatídica estrella en el Quijote (I, 43-45)
}

Frederick De Armas

Universidad de Chicago, Estados Unidos

fdearmas@uchicago.edu

Recibido:31/12/2019. Aceptado: 13/6/2020.

\begin{abstract}
Resumen
La sexta novela intercalada en la primera parte del Quijote comienza con una canción de don Luis, que, disfrazado de mozo de mulas, sigue a su amada. En la canción, don Luis se dibuja a sí mismo como marinero de amor y como nuevo Palinuro. Esta referencia es al piloto timonel en la Eneida de Virgilio. Tras recordar la importancia de esta figura clásica en el Siglo de Oro, analizamos la sombra trágica que deja este Palinuro dentro del texto. La fatídica contemplación de su estrella puede llevar a don Luis a un fin desastroso. Ya que Palinuro, en la Eneida, muere como sacrificio a Neptuno, hay que considerar que el futuro viaje de Clara y de su padre a América no carece de peligro; lo mismo puede decirse del viaje de don Luis a Andalucía, acompañado por don Fernando, conocido por sus traiciones.
\end{abstract}

\section{Palinuro and his Fatidic Fate in Cervantes' Don Quixote}

\begin{abstract}
The sixth interpolated tale in the first part of Don Quijote begins with a song by Don Luis, who disguised as a muleteer, follows his beloved. In the song, Don Luis portrays himself as a mariner of love and as a new Palinurus. This is a reference to the pilot in Virgil's Aeneid. After delineating the importance of this classical figure in the Spanish Golden Age, this essay analyzes the tragic shadow that Palinurus projects into this tale. The fatidic contemplation of his star may well lead Luis to a disastrous end. Since Palinurus, in the Aeneid dies as a sacrifice to Neptune, one must consider that the future voyage of Clara and her father to America could be a dangerous one. The same can be said of Luis' travels to Andalucía, since he is accompanied by Don Fernando, known for his treachery.
\end{abstract}

Palabras clave

Neptuno Eneida Palinuro astrología novela intercalada

Keywords Neptune Aeneid Palinurus astrology interpolated tale 
1. "El contacto previo de los cabreros con el astrólogo, conocedor él de estrellas igual que lo eran ellos, explicaría el que los cabreros se inclinasen por defender a Grisóstomo en la historia del amor no correspondido" (Schmidt, 2012: 186). A pesar de los conocimientos astrológicos

de Grisóstomo, para Schmidt,

"el antiguo discurso astrológico

fracasa ante la invisibilidad de la vida interior del ser humano" (195).

2. Sobre los bueyes como animales que tiraban el carro de Saturno, dios planetario, verse los estudios de Fajardo (1986) y De Armas (2011).

3. "As the visionary whose absolute monarchy established the model for the dominant form of rule in Europe for the next two centuries, Philip deeded to posterity living proof that the Hapsburg

heir was decreed by God to be the Last Descendant of Aeneas. The epithet refers to the advent of millennial peace when, having defeated the heretic and unified the hemispheres in the Christian rule under his rule, the successor of Aeneas yields the terrestrial rule back to Christ" (1993: 145).

4. También se incluye su nombre dentro de un catálogo sobre los peligros de la navegación en una comedia de Agustín Moreto, Los hermanos encontrados.
Más de una vez, la primera parte del Quijote se refiere a "la ciencia de las estrellas" $(\mathrm{I}, 12),{ }^{1}$ sea ya para recordar los estudios de Grisóstomo en Salamanca o para determinar la hora a través de los signos celestiales (I, 20). Incluso hay instancias en que la astrología se esconde dentro de la narrativa, como en el carro encantado que lleva a don Quijote de vuelta a su casa pero que esconde imágenes del desdichado carro de Saturno. ${ }^{2}$ Parece ser que en casi todas, si no todas las instancias en que se alude a la astrología, tenemos sustos, desgracias o tragedias. Aquí quisiera estudiar una mención que parece particularmente ambigua.

Llegando al fin de la primera parte del Quijote, comienza la sexta de las siete novelas intercaladas con unas redondillas cantadas por un nuevo Palinuro. Una primera lectura podría sorprender ya que se evoca a un personaje de la épica clásica en una canción de amor. No solo se encuentra en una novelita amorosa este extenso recuerdo del piloto o timonel de la nave de Eneas, sino que se halla en un momento que no parece acercarse a la épica. En estas páginas intentamos vislumbrar la sombra trágica que deja este Palinuro dentro del texto y la fatídica contemplación de su estrella. Antes de proceder a este análisis, como breve introducción valdría recordar dos elementos: la importancia de esta figura en el Siglo de Oro y la huella épica en la obra cervantina.

\section{El Palinuro Imperial}

Palinuro aparece como figura sombría en el Siglo de Oro, pero siempre partícipe del comienzo del imperio romano, como bien lo canta Virgilio. Después de todo, como piloto de la nave de Eneas, es figura clave para que el héroe llegue a su destino. Y como si esto no fuera suficiente, Palinuro se transforma en sacrificio. Venus, madre de Eneas, preocupada por la ira de Juno, le pide a Neptuno, dios de los Océanos, que le conceda el don de que su hijo llegue a Italia sin accidente. En el quinto libro de la Eneida, el dios marino le concede esta merced a Venus, pero le revela que uno de los muchos compañeros de Eneas tendrá que morir: "unum pro multis dabitur caput" (5.815). Este será justamente el piloto de Eneas. El libro quinto termina con la aparición de Somnus y la caída de Palinuro al mar. Se trata pues de un sacrificio que salva a los ancestros de los romanos; y un sacrificio que recae sobre uno de los más fieles compañeros de Eneas que siempre está vigilando los cielos y las estrellas para prevenir todo peligro. Esta escena no podría pasar inadvertida en España, ya que los reyes de la Casa de Austria, como bien ha mostrado Marie Tanner, se consideraban los últimos descendientes de Eneas. ${ }^{3}$

Es bajo este manto imperial donde lo hallamos, aunque escondido, en tres textos del Siglo de Oro algo posteriores al Quijote. Hay un breve pero importante momento en $E l$ Aquiles de Tirso de Molina, donde Ulises, en busca de Aquiles -quien está escondido y vestido de mujer ya que su madre no quiere que participe en la guerra de Troya- se llama a sí mismo Palinuro. El nombre solo se menciona una vez en la tercera jornada. Cuando le preguntan su nombre, Ulises, disfrazado de mercader, responde: "Palinuro" (1946: 1936). Esta alusión al piloto de Eneas sirve como elemento de anticipación, vaticinando no la muerte de Ulises, sino la de Aquiles en el cerco de Troya. Con Aquiles como nuevo Palinuro se subraya la muerte de dos figuras de campos opuestos, figuras cuyos sacrificios son claves para el éxito. Aquiles tiene que morir en el cerco y Palinuro tiene que perecer en el viaje a Italia, de allí donde surgirá el imperio romano. Se trata pues del sacrificio necesario para el triunfo de los griegos en Troya y el levantamiento de un nuevo imperio romano con los pocos troyanos que han sobrevivido.

La Soledad Primera puede servir de contraste ante esta visión imperial triunfalista y sin recelos. Góngora alude al piloto de Eneas como parte de una crítica contra la navegación (1994: v. 398). ${ }^{4}$ Para Mary Gaylord, este lamento representa "an island of sense in a sea of obscurity" (1978-79: 100), ya que claramente condena la navegación 
como instrumento de conquista e imperio. Esta condena se subraya al fin de la escena cuando aparece la figura alegórica de Codicia como piloto de una inmensa flota. ${ }^{5}$ Aun así, el rumbo es claro: la conquista imperial que satisface la codicia.

Muy diferente y barajando elementos amorosos, épicos y caballerescos es la alusión a Palinuro en El conde Partinuplés de Ana Caro. Aquí, el amante, heredero de la corona de Francia, viaja en una nave mágica típica de los libros de caballería. La nave no tiene piloto, pero conoce muy bien su rumbo: el palacio de la desconocida mujer a quien ama Partinuplés, la emperatriz de Constantinopla. Cuando el caballero exclama que el viaje va más allá de lo que se puede creer, el gracioso se muestra contento: "Yo sí, / (después de tanto tormento) / es ver un navío seguro / sin piloto, Palinuro..." (1997: vv. 762-66). La presencia del seguro navío como figura de Palinuro en Ana Caro incluye entonces elementos de conquista amorosa e imperial que tipifican el uso del piloto de Eneas en el Quijote de Cervantes.

No debe sorprendernos la presencia de Palinuro en la gran novela cervantina. No solamente es parte del imaginario imperial del Siglo de Oro, sino que Cervantes construye el Quijote con el poema de Virgilio en mente; y puede que también recuerde la Odisea homérica. En realidad, el episodio de Palinuro, como subraya David Quint, es una imitación de la tormenta homérica en el libro 12 de la Odisea. ${ }^{6}$ La canonización del Quijote tuvo mucho que ver con la épica. La primera gran edición anotada de la obra en España fue editada por Vicente de los Ríos en 1780. Entronca claramente al Quijote dentro de la tradición de la epopeya. Para de los Ríos, Cervantes es un nuevo Homero: "Ambos fueron poco estimados en sus patrias, anduvieron errantes y miserables toda su vida, y después han sido objeto de la admiración y del aplauso de los hombres sabios en todas las edades, países y naciones" (1819: 14). Muestra, por ejemplo, que el yelmo de Mambrino tiene precedentes en las armas de Aquiles, en el escudo de Eneas y en otros objetos forjados por Vulcano en la literatura clásica. ${ }^{7}$

Ya hace unas siete décadas Arturo Marasso afirmó que Cervantes no solo utilizó una edición latina del poema, sino también dos traducciones al español, la de Gregorio Hernández de Velasco y la de Diego López. Michael McGaha asevera que Cervantes sigue a Virgilio, aunque rechaza la presencia de tres elementos claves del poema. ${ }^{8} \mathrm{Y}$ el más virgiliano de los lectores de Cervantes, Antonio Barnés Vázquez, afirma: "Si la literatura caballeresca incitó a don Quijote a la acción", entonces "el universo grecolatino dotó de contenido a esta misión" (2009: 138). Todo esto es cierto, pero la historia o narrativa de Cide Hamete constantemente traiciona al caballero:

\begin{abstract}
Anhela tener un texto unificado que lo guíe y lo lleve a la victoria. Sus narradores lo traicionan al contar lo mínimo y lo ratero, al llevarlo a Sierra Morena, sitio de muertes farsálicas y falto de dioses (aunque don Quijote cree que se esconden las nereidas en esa foresta). El ideal virgiliano del caballero se desmorona frente a los ataques textuales (De Armas, 2010: 206).
\end{abstract}

De allí que resulta sumamente interesante encontrar a un personaje de la Eneida en una narrativa intercalada en el Quijote, novelita fragmentada en parte por el caballero manchego quien alterna entre ser burlado y alcanzar una nueva voz. ¿Se trata de un momento que ensalza o cuestiona el ideal virgiliano? ¿Es Palinuro figura de esperanza o de frustración y tragedia?

\section{La canción de Luis/Palinuro}

Para E. C. Riley esta novela intercalada es muy curiosa ya que no tiene firme resolución y es una de las menos desarrolladas. Los amores de Luis y Clara se presentan
5. “Greed personified captains every ship, bringing distant lands together only to violate them" (Padrón, 2007: 367).

6. "Aeneas and his companions are thus twice saved from storms that threaten them with the fate of Odysseus' men and in both cases the helmsman dies... Books emphasizes the sacrificial substitution that is taking place by splitting off the death of Palinurus into a separate episode at the book's end" (89).

7. de los Ríos encuentra toda una serie de paralelos con poemas épicos. Por ejemplo: (1) las bodas de Camacho se relacionan a los juegos funerarios para Patroclo en la llíada y los juegos celebrados por Eneas en el aniversario de la muerte de Anquises (1819: 27-39); (2) el descenso a la Cueva de Montesinos recuerda los viajes a los infiernos de Ulises y de Eneas (1819: 45).

8. Los tres elementos son la intervención de los dioses en los eventos humanos, lo maravilloso y el uso de la magia (1980: 44-46). 
9. Sobre la falta de título de capítulo en la primera edición ver Flores (1979: 135-60) y Martín Morán (1990: 15).

10. Se cita el Quijote por la edición de F. Rico, Madrid, 2007.

11. El soneto del Persiles, "Mar sesgo, viento largo, estrella clara”, está puesto en boca del portugués Manuel de Sosa y Coitiño y dedicado a su amada Leonora Pereira. Según Lozano, Cervantes se desvía de la tradición petrarquista de varias maneras, incluyendo que ahora la nave es la dama y no el amante masculino. Añade que en "el soneto cervantino el mar y el viento no se confabulan para entorpecer el curso de la nave. Todo lo contrario, se alían con la estrella para conducirla a puerto seguro" (2004: 303). Lo mismo ocurre en la canción en el

Quijote, donde don Luis como piloto se encuentra en un mar calmado y sigue firmemente su estrella, esperando llegar a puerto seguro. Ya

Pedro Ruiz Pérez había apuntado a este soneto como obra que va más allá del petrarquismo y ejemplo de manierismo, rompiéndose la unidad temática "escindida en dos polos que se corresponden con aquellos en los que se mueve toda la novela: el mar y el amor" (1985: 172). Parece como si descartara el amor hasta fines del poema, donde se retoma en el último terceto.

12. Antonio Barnés Vázquez nos da una clara visión del poema en su totalidad: "Él es un marinero y el amor es su mar. Su amada es su estrella, y las nubes los obstáculos que ella interpone" (2009: 230).

13. Ahora bien, se podría aseverar que don Luis rechaza las estreIlas de Palinuro: "Luis rejects

Palinurus's stars. Luis has only to follow one star, Clara. Love has thus become an epic quest" (De Armas, 2011: 141). Pero creo que Clara refleja una estrella específica entre las nombradas por Palinuro.

14. Ya en su descripción de los murales en el templo de Dido,

Virgilio había aludido al efecto a veces maléfico de las constelaciones, tales como las lluviosas Híades y Arturo (Putnam, 1998: 48).

15. De esta muerte hacen eco escritores modernos para comentar

la soledad del ser humano. Ver, por ejemplo, a Palinuro de México (1977) del novelista mexicano

Fernando del Paso; y Cyril Connolly, quien en The Unquiet Grave [ $\mathrm{La}$ tumba sin sosiego] analiza su vida (cambiando su nombre por el de Palinuro). En The Cabala, de Thorton Wilder, Samuele examina las estrellas utilizando ecos virgilianos antes de regresar de Nápoles a América, haciendo así el viaje virgiliano a la inversa, regresando a casa (Rojcewicz, 2018: 154). como "Un simple esbozo, en parte narración, en parte acción, un relato de amor juvenil, una simple aventura llevada... a un esperanzador desenlace" (Riley, 2000: 106). Más que esbozo, diríamos que se trata de figuras de un tapiz finamente hilado que entrelazan a los amantes con otros personajes en la venta, permitiendo así una serie de perspectivas y puntos de vista. El capítulo 43 comienza con una canción de un personaje disfrazado de mozo de mulas que permanece en la intemperie, a quien escucha Dorotea desde la venta mientras duerme doña Clara: ${ }^{9}$

\section{Marinero soy de amor \\ Y en su piélago profundo \\ Navego sin esperanza \\ De llegar a puerto alguno.}

Siguiendo voy una estrella
Que desde lejos descubro
Más bella y resplandeciente
De las que vio Palinuro. $(1,43: 446)^{10}$

Mientras que Alberto Sánchez en su estudio sobre los romances en la obra cervantina alaba este ya que es "de mayor emoción e intensidad lírica" (1991: 259), Diego Clemencín pone reparos a la utilización del personaje de Palinuro ya que "esa especie de pedantería en el romance era propia de un mozuelo que estudiaba a Virgilio, y acomodaba sus estudios a sus amores" (1833: 2.270). Pero, como ya hemos constatado, don Luis no es el único personaje del Siglo de Oro que se disfraza o imagina como un nuevo Palinuro. Desde el Ulises de Tirso hasta la barca que lleva a Partinuplés a seguro puerto en Ana Caro, Palinuro revela el rumbo del imperio y del amor. El piloto cervantino va mucho más allá de lo que Clemencín llama pedantería y se convierte en mito clave para la comprensión de la novela intercalada.

En esta canción Cervantes desarrolla la conocida metáfora de la nave de amor, de muy antiguos orígenes. En su estudio de un soneto sobre este mismo tópico y con lenguaje curiosamente similar, pero hallado en el Persiles y Sigismunda, Isabel Lozano Renieblas recuerda que "se inscribe en esta tradición de la lírica petrarquista en la que son frecuentes las metáforas que relacionan al amante con un navegante, piloto o marinero, y no solo en la lírica de Petrarca y sus contemporáneos sino también en la lírica de los siglos posteriores" (2004: 301). ${ }^{11}$ El poema revela que don Luis es un marinero de amor y que la estrella que sigue es clara, así aludiendo al nombre de su amada. ${ }^{12} \mathrm{Al}$ igual que Palinuro, Luis debe de mirar fijamente a las estrellas y constelaciones para llegar a su destino sin saber cuál es. En términos astrológicos, la constelación de las Pléyades enlaza esta novela con la anterior, la de Zoraida. ${ }^{13}$ Pero la presencia de Arturo entre las constelaciones que observa el Palinuro de Virgilio puede tener sentido tanto como signo de Clara, como de signo ominoso. Se trata de la estrella más brillante en la constelación de Bootes, inmensa figura humana que mira hacia la Osa Mayor y que se identifica con una serie de labradores o agricultores. Su nombre significa boyero o conductor de bueyes. Lo clave aquí es que muchas veces augura tormentas. ${ }^{14}$ Es como si Palinuro mirase fijamente a la estrella Arturo en esta constelación para saber por dónde navegar. Junto a ella se hallan las Híades, estrellas que también auguran tormentas. Como bien explica Robert Hannah, "both Arcturus and the Hyades are to be found in those ancient weather almanacs, the parapegmata, as signs of bad weather" (1993: 126). Y ya que Arturo es una de las tres estrellas más brillantes en los cielos, puede muy bien recordar a Clara por su clara luz. Luis sabe muy bien transformar la épica virgiliana en un momento lírico donde él como amante sigue a su estrella. Pero, al mismo tiempo propone estrellas peligrosas y escoge una historia trágica, ya que el Palinuro de Virgilio morirá en tierra extraña, como fin de su viaje. ${ }^{15}$ Es cierto que el poema cervantino utiliza la muy conocida imagen de la 
muerte de amor: "Al punto que te me encubras / será de mi muerte el punto" (I, 43: 447). Aun así, el miedo de las nubes que pueden encubrir la estrella, y la incertidumbre de la ruta, se conjuran como fuerzas amenazantes que van más allá de la metafórica muerte de amor.

Luis, disfrazado de mozo de mulas, ha seguido a Clara desde la corte. Al encontrarla en la venta, canta "Marinero soy de amor", causando la admiración de Cardenio y Dorotea. Esta despierta a Clara, quien inmediatamente reconoce la voz, dándole "un temblor tan extraño" (I, 43: 447). Comprendemos entonces que Clara conoce y está enamorada del "desdichado músico" (I, 43: 447). El hecho de que duerma durante su primera canción, la de Palinuro, puede muy bien tratarse de un momento anticipatorio. Después de todo, la imagen del sueño apareció ante el piloto virgiliano instándolo a que durmiera. Pero, observándola, Palinuro le pregunta: “¿Es a mí a quien aconsejas que olvide lo que pueden ocultar la faz apacible del mar y esta serenidad de las aguas? ¿Supones que debo fiarme de calma tan prodigiosa?... Habla de este modo sin soltar el timón, antes bien estrechándolo más con los ojos fijos en las estrellas" (Eneida, 5, 845-55). La vigilia de Palinuro es constante. No es hasta que el sueño le toca las sienes con "una rama humedecida de las aguas de Leteo y vigorizada por la virtud de la laguna Estigia" (Ibid., 850-55) que Palinuro se duerme, cayendo su cuerpo en las tranquilas aguas. Lo importante aquí es que a través de una inversión de roles tenemos una anticipación profética: Clara duerme durante la canción de su Palinuro y aun cuando Dorotea la despierta no quiere escuchar el siguiente canto, tapándose los ojos y oídos "para no ver ni oír a ese desdichado músico" (I, 43: 447). O sea, ella duerme y quiere seguir adormecida sin escucharlo, además de considerarlo desdichado. El sueño le trae desdicha a Palinuro.

\section{La desdichada Dorotea}

Jean Canavaggio nos recuerda que las canciones y la reticencia de Clara intensifican la curiosidad del lector, el cual quiere escuchar la novela; es decir, lo que Clara le revela a Dorotea (2005: 15). Pronto aprendemos de ella que Luis vivía "frontero de la casa de mi padre en la corte" (I, 43: 449), y pasando el tiempo se enamora de Clara, hablándose por señas. Este amor por vista y señas parece haberse deshecho cuando el padre de Clara anuncia su partida a las Indias, donde ha recibido un importante puesto. Clara comprende entonces que su amor es imposible, algo que ya intuía pues el padre de Luis era de rango superior al suyo: “¿Qué fin se puede esperar si su padre es tan principal y rico, que le parecerá que aun yo no puedo ser criada de su hijo, cuanto más esposa?" (I, 43: 450). Puede que no sea casualidad que Clara le confiese sus amores a Dorotea pues esta también tenía un amante de más alto rango. ${ }^{16} \mathrm{R}$. M. Flores ha notado que solo dos de las novelas intercaladas tienen conclusión definitiva, la de Grisóstomo y Marcela, y El curioso impertinente. Por el contrario: "No se nos dice si tres parejas (el Cautivo y Zoraida; doña Clara y don Luis; Cardenio y Luscinda) acabaron casándose, pero no hay duda alguna en la mente del lector que tal fue el caso" (1995: 461). Muy diferente, apunta, es el caso de Fernando y Dorotea. Él, faltando a su palabra, la abandona. Además, se enamora de la amada de Cardenio cuando la ve por la ventana y traiciona a su amigo para casarse con Luscinda. ${ }^{17}$ Por su parte, Dorotea, vestida de hombre, trata de hallar a Fernando, sufriendo engaños y trabajos. Para Anne J. Cruz, Dorotea es más fuerte y virtuosa que Luscinda. Se adentra en el mundo y sus peligros, siempre virtuosa. De esta manera, supera con sus obras la nobleza de Fernando: "for the purpose of realist narrative, marriage to Fernando is also the means by which she achieves a degree of social success... By virtue of her virtue, she is his equal when nobility is measured by conduct and not by birthright" (2005: 630).
16. David Quint explica: “Don Quijote may aspire to wed his princess... but it is the women, Dorotea and Clara, who marry up" (2003: 75).

17. Anne J. Cruz demuestra que Fernando es una figura que se aleja de lo moral para deleitarse con la pasión: "his amoral cunning and uncontrolled passion" (2005: 622). 
18. Flores incluye entre otras razones: "(1) don Fernando nunca habló con los padres de Dorotea a pesar de las cartas, regalos y flores que llegaban a manos de la labradora, a todas horas y las constantes músicas con que regalaba sus oídos noche y día; (2) que los padres de Dorotea nunca habían visto con buenos ojos lo que estaba sucediendo" (1995: 464). Ahora bien, mi opinión es que los padres de ella aceptarían con alivio y hasta alegría el casamiento de Fernando y Dorotea.

19. Flores asevera: "Deus ex machina y cae el telón... Es imposible aceptar que el egoísta, violento y empedernido Don Juan cambie de un minuto a otro y se convierta en un don Fernando amoroso, noble y generoso" (1995: 464-65).

20. Carroll B. Johnson nos recuerda que el juez u Oidor es tanto el hermano del cautivo como el padre de Clara, enlazando de esa manera las dos novelas intercaladas (1982: 144).

21. "Tomad, señora, esa mano, o, por mejor decir, ese verdugo de los malhechores del mundo; tomad esa mano, digo, a quien no ha tocado otra de mujer alguna, ni aun la de aquella que tiene entera posesión de todo mi cuerpo" (I, 43: 453). Sobre la corporalidad de este episodio ver el artículo de Gaylord (1993).
Cuando Fernando y Dorotea se encuentran en la venta, ella pide casamiento, no por amor sino por honor: "Desesperación y no amor es lo que sus palabras describen al vivo" (Flores, 1995: 462). Aunque Fernando parece prometerle casamiento por segunda vez, conocemos bien su duplicidad. De todas las razones para dudar del futuro casamiento entre Dorotea y don Fernando, tres son para mí las de mayor importancia: 1) Fernando solo quiso gozarla y nunca la amó; 2) los padres de Fernando, siendo de alta nobleza, no consentirían este casamiento; 3) su sí es ambivalente: "y pues ella [Luscinda] halló y alcanzó lo que deseaba... yo rogaré al cielo que me los deje vivir con mi Dorotea" (I, 36: 382).${ }^{18}$ Es como si el fementido don Fernando, todavía celoso de que su Luscinda se casara con Cardenio, dice que hará lo mismo con Dorotea. ${ }^{19}$ Ya que hay tanta incertidumbre en torno al futuro de Dorotea, podríamos preguntarnos por qué es ella la que escucha la voz de don Luis marinero y se convierte en la intermediaria entre Luis y Clara. ¿Se trata de un nuevo presagio ominoso?

\section{Palinuro en puerto seguro}

El canto de este nuevo Palinuro no es simplemente una canción de amor, sino que tiene elementos épicos como en otros textos de la época. Es cierto que, mientras que Eneas debe abandonar a Dido para alcanzar su objetivo épico-imperial, Luis solo tiene que seguir a su amada y dejar que la luz de su estrella ilumine su viaje de amor. Pero el mar de amor puede ser mal de amor; en el mar pueden surgir tempestades muy peligrosas, siendo bien conocida la ecuación mar/fortuna. Carlos Mata Induráin subraya que en este romance hay toda una serie de "imágenes o expresiones negativas que nos hablan de ese peligro que le amenaza" (2007:136). Puede que Luis piense que la venta en la que encuentra a Clara es como un puerto seguro, lejos de la mala fortuna y de la tormenta. Pero surge una metafórica tempestad justo dentro de la venta. Cuatro de los sirvientes del padre de Luis, que lo han seguido, llegan a la venta para llevarlo a casa. Recordemos que, en la Eneida, Neptuno le había vaticinado a Eneas que llegaría a puerto seguro, pero que sacrificaría a uno de los suyos para hacerlo. Aquí parece como si Luis, nuevo Palinuro, siguiendo tan firmemente su estrella, fuera acechado por un dios que busca deshacer su visión de amor.

Por otra parte, el padre de Clara, Juan Pérez de Viedma, una vez que se entera del asunto, parece tener muchos menos impedimentos ante tal relación y futuro matrimonio. Podría ser que lo viera como un casamiento por destino, ya que don Luis le asegura: "Por ella dejé la casa de mi padre, y por ella me puse en este traje para seguirle dondequiera que fuese como la saeta al blanco o como el marinero al norte" (I, 44: 462). Por otra parte, puede que piense que este casamiento le trajera gran beneficio, siendo Luis hijo de un importante caballero. ${ }^{20}$ Parecería entonces que el motivo común de la conquista y los viajes a las Indias se aúnan aquí con la codicia, o al menos el deseo de ganancia por parte del padre de Clara, recordando así a la Soledad Primera, donde Góngora menciona al piloto de Virgilio (v. 398). Aunque no cabe duda de que la codicia, la conquista y el amor se entrelazan en estos episodios, parecen casi sumergirse estos tópicos ante tantos conflictos y batallas que se desatan en la venta. Dominick Finello explica: "Their modest story possesses the substance of an idyll that is fragmented by the broader narrative of the adventures of the inn" (1994: 112). El idilio amoroso contrasta inmediatamente con los amoríos de don Quijote y Maritornes. Queriendo vengarse del caballero, la moza pretende estar perdidamente enamorada y le pide la mano, escondiéndose tras una ventana o hueco en el pajar. ${ }^{21} \mathrm{Al}$ subirse sobre Rocinante y darle la mano, el caballero es fácilmente burlado. Maritornes deja a don Quijote con la muñeca atada, de pie sobre Rocinante, esperando que el caballo no se mueva para no quedar colgando de la cuerda. Esta escena entremesil que se burla de amores idílicos ocurre justo después de la llegada de Luis como marinero de 
amor y mozo de mulas. Cervantes entreteje motivos tales como la falta de ventanas -sea en la venta o en la casa del padre de Clara en la corte- para darle al lector una visión de diferentes tipos de amor. Desde sus ventanas en la corte, Luis se compromete a casarse con Clara: "Entre las señas que me hacía, era una de juntarse la una mano con la otra, dándome a entender que se casaría conmigo" (I, 43: 449). Maritornes utiliza mano, palabras y señas para burlarse del caballero. No sabemos si el desastre de don Quijote contrasta con un futuro próspero o si apunta al fin de los idilios entre Luis y Clara.

No es esta la única narrativa que compite con la fragmentada historia de Luis y Clara. Una narración mucho más completa e impactante la había precedido, aunque no podemos detenernos en ella. Ruy Pérez de Viedma, el cautivo, hermano del padre de Clara, ha regresado del otro lado del Mediterráneo con Zoraida/María, viaje accidentado donde se necesitaba un buen piloto que siga a su estrella. El nombre arábigo que le corresponde a Zoraida es Turayya, o al-Thurayya, o sea, la constelación de las siete hermanas o cabritas, las Pléyades (Camamis, 1977: 81). ${ }^{22}$ Vemos entonces cómo el firmamento se impone una y otra vez en estas narrativas. Y sea en el caso de Zoraida o en el de Clara, hay algo celeste o sobrenatural que pone en duda el éxito del amor. Las Pléyades pueden significar la estación propicia para la navegación, pero también auguran tormentas y catástrofes (Allen, 1963: 391-403).

\section{Viajes y triunfos amorosos e imperiales}

También en estos capítulos don Quijote tiene su visión más heterodoxa: imagina todas las disputas en la venta como las contiendas en el campo de Agramante. Todos allí son sarracenos y no caballeros cristianos. ${ }^{23} \mathrm{El}$ cura es un nuevo Agramante, líder del cerco de París, mientras que el padre de Clara es el Rey Sobrino, consejero de Agramante. Como por arte de magia, don Quijote parece apaciguar a los sarracenos: "Ténse todos, todos envainen, todos se sosieguen, óiganme todos, si todos quieren quedar con vida" (I, 45: 470). Aunque llegue esta paz en el campamento, Ariosto (la fuente de este episodio) cuenta que los sarracenos pierden la batalla y tienen que regresar al otro lado del Mediterráneo. Eneas y Palinuro hacen la travesía contraria, desde las costas africanas hacia Italia en busca de un nuevo imperio. Puede que la historia de Luis se pierda y se anegue entre tantas otras; que Luis esté perdido en una venta convertida en tempestad marítima y que busque madero o tierra con que salvarse. Recordemos que Palinuro no muere en el mar, sino que después de tres días y tres noches en las aguas, llega a una tierra salvaje en el sur de Italia donde es asesinado en las arenas de la orilla por los Lucani. Parece entonces que toda una serie de narraciones revelan su oposición a los amores del nuevo Palinuro: Maritornes se burla de amores idílicos, mientras que los sarracenos del caballero tienen que regresar a su punto de origen. ¿Se trata de un amor imposible? La paz que ha establecido don Quijote en la venta, aunque muy precaria, hace eco de las varias soluciones a los diferentes conflictos. Tras muchos lances y palabras, tres de los criados regresarán a la corte y le informarán al padre de don Luis de lo ocurrido, mientras que el cuarto acompañará a Luis a las tierras del marqués, hermano de Fernando en Andalucía, donde el joven enamorado "sería estimado como el valor de don Luis merecía" (I, 45: 471).

Esta solución baciyelmesca ayuda a calmar a don Luis, que repite una y otra vez que no regresaría a casa de su padre. Asimismo, deja abierta la posibilidad de un matrimonio entre don Luis y Clara. Parecería que todo tiene que ver con el amor, pero estos capítulos también tratan de viajes y conquistas imperiales. Juan Pérez de Viedma va hacia las márgenes del imperio, habiendo aceptado un puesto de importancia en México y parece que lleva consigo a su hija Clara, aunque lo de un matrimonio futuro todavía se cuenta como posibilidad. El hermano de Juan también
22. Aunque Alberto Montaner Frutos prefiere otras interpretaciones de gran interés, la relación de Zoraida con las Pléyades es subrayada por otros críticos. Según Maria Antonia Garcés: "This luminous vision recalls the symbolism of Zoraida's name, pleiad, cluster of stars" (2002: 215). Ahora bien, en el episodio de Palinuro, el cual imita el viaje de Ulises desde la isla de Calipso, Virgilio elimina las Pléyades e incluye en vez las Híades (Brown, 1990; Hannah, 1993). Si Cervantes quiere subrayar la importancia de las Pléyades, ¿cómo interpretar el episodio de Palinuro donde Virgilio borra esta constelación?

23. Para un detallado análisis del episodio de la venta como conflicto en el campo sarraceno de Agramante ver a de Armas (2011: 146-61). 
24. Según Carroll Johnson, la historia del capitán cautivo incluye referencias de gran interés: “The gratuitous presence of these French Protestants, together with the mention of the rebel heretics in Flanders and not one, but two periods of captivity among the Muslims" se entrelazan, ya que Cervantes cuestiona "the role of imperial, Catholic Spain in a world becoming increasingly, irredeemably pluralistic" (1982: 139-40).

25. Con base en las teorías de Josiah Blackmore y Darlene Sadlier, Ana Laguna, en su estudio del episodio cervantino de la barca encantada, explica: "Direct or indirect critiques of the imperial project are indeed blended into the vivid, touching, and agonizing stories of the deaths of sailors and castaways, making these narratives hardly reconcilable with the official, triumphant claims about oceanic expansion" (2019: 187). De esta manera, Laguna y otros críticos llegan a afirmar que las metafóricas tormentas del Quijote pueden recordar las que cuestionan y ponen en peligro los viajes y el proyecto colonizador americano.

26. En La Dorotea, César, invocando las preocupaciones del filósofo Marsilio Ficino sobre la influencia de Saturno, explica lo difícil que es curar la enfermedad de amor: "y en los hombres melancólicos más que en los joviales y alegres; y más si tienen a Saturno con Marte retrógrado" (Lope de Vega, 1968: 406).

27. "Placed at the end of Book 5 , the death of Palinurus is thus the fourth in the series of deaths

-following those of Creusa,

Anchises and Dido- that have stripped Aeneas of personal ties and identity and it stands to argue, for the sacrifice that Aeneas, in his role as leader of the Trojan mission, must make of his own individuality, even of his heroic agency in the poem... in marked contrast to the model of the Odyssey and its individualistic hero, a model that Vergil's episode inverts and rejects" (Quint, 1993: 84). desea casamiento, en su caso con Zoraida/María. El cautivo y la mora han cruzado el Mediterráneo no sin tormentas y peligros. El mar, entonces, se convierte en un sitio donde se dramatizan los riesgos, los atractivos y las tentaciones de un imperio; señala las próximas y lejanas márgenes de la España imperial dentro de un mundo cada vez más complejo. ${ }^{24}$ Mientras que el Mediterráneo sigue siendo un mar peligroso con corsarios islámicos, el gran océano que llevará al oidor al Nuevo Mundo también es lugar de terribles tormentas. ${ }^{25}$ Navega a un sitio todavía aún más incomprensible para el europeo que el norte de África, lugar de seres y costumbres hasta hace poco nunca imaginadas.

Al invocar a Palinuro y a las estrellas en que se fija, don Luis, sin saberlo, ayuda a forjar unos capítulos que tratan de riesgos amoroso-imperiales. Son capítulos donde la codicia esparce su reino ya que el Nuevo Mundo es sinónimo de riquezas. Así, el oidor incluye a México y a Clara como sitios o cuerpos de lucro. Puede que Clara sea la estrella de don Luis, pero en sus contextos virgilianos puede ser Arturo, la más clara estrella de la constelación de Bootes, índice de tormentas. Bootes, al mismo tiempo, es figurado como labrador que conduce bueyes. Esta imagen puede traducirse en términos de Saturno, el más maléfico de los planetas. Después de todo, el carro planetario de este dios es siempre conducido o por dragones o por bueyes. Y los últimos capítulos del Quijote, donde el caballero regresa a su casa encerrado en un carro conducido por bueyes, han sido interpretados en términos de Saturno (Fajardo, 1986; De Armas, 2011). Saturno es el planeta de frustraciones y desgracias. Así, Clara, como la más clara (y peligrosa) estrella en la constelación de Bootes, puede muy bien significar que el deseo de los amantes se verá frustrado. Al igual que Lope de Vega en muchas de sus obras, aquí Cervantes parece incluir a Saturno como figura de desgracia en el amor. ${ }^{26}$

Clara, convertida en estrella fatídica, es entonces la luz de don Luis, nuevo Palinuro. Al invocar a Palinuro, se subraya de nuevo el peligro del viaje. Después de todo, sabemos que un viaje como el del oidor puede conllevar un nuevo sacrificio a Neptuno. El viaje de don Luis a Andalucía no carece de peligros, y no se trata solo de bandidos. Fernando había traicionado a su amigo Cardenio casi sin importarle lo que hacía. Las casas de los grandes pueden ocultar peligros y traiciones, un rasgo del muy conocido motivo de la alabanza de aldea y menosprecio de corte. Según David Quint, la muerte de Palinuro es solo un sacrificio más que libera a Eneas y le facilita sus conquistas. ${ }^{27}$ Eneas tuvo que abandonar a Dido, dejarla del otro lado del Mediterráneo para poder continuar su ruta imperial. ¿Deberíamos entonces pensar que todos los amores en estos capítulos van a fracasar, que ambas, Zoraida y Clara, serán abandonadas? Y el piloto que debe ser sacrificado, ¿es simplemente don Luis o también el oidor que pasa a México?

La canción de don Luis/Palinuro es tan luminosa como sombría, brillando bajo la luz de su estrella Clara/Arturo y temiendo las oscuras nubes, la tempestad forjada por los dioses o por la fortuna. Esta oscuridad no se disipa con el brillo del baciyelmo, ya que hace eco de la confusión del marinero, de la confusión en la venta y de la confusión que emerge de los múltiples relatos fragmentados. Nuestro Palinuro, que ha seguido tan firmemente su estrella, ahora se desvía a casa de un marqués: la solución no es suya, el futuro no le pertenece. No podemos creer que se trate de una deserción en un momento tan cerca del triunfo amoroso. El marinero de amor había afirmado que nunca dejaría de ver su estrella, pero ahora parece que su nuevo guía es Fernando, sabio en traiciones, en arreglos furtivos y en las artimañas de la alta nobleza. Parece que nuestro Palinuro va a recibir una nueva educación cortesana en casa del marqués, sitio donde podría perder sus ideales y su inocencia. Hasta el momento, parece estar dentro de la estructura cósmico-amorosa de su entorno, relacionando los cielos con la amada, el macrocosmos con el microcosmos. Una 
vez que se desvíe, corre el riesgo de perder su guía y su estrella, y de hallarse en condiciones de abandono y solitud cósmica y emocional, perdiendo así el firme rumbo de su vida. Cervantes nunca quiso darnos el final de varias de sus aventuras. Puede que solo haya podido sugerir posibles desastres en un texto que debería ser festivo aunque acabe con el triste retorno de don Quijote a su casa, viaje en un carro encantado y conducido por bueyes, que parodia las difíciles rutas de Fernando y Dorotea, el Cautivo y su amada, y de un Palinuro que ahora parece andar sin rumbo, ocultándose su clara estrella. ${ }^{28}$
28. De Cartago a Italia, de África a París, de Aragón a las Indias, de Argel a Andalucía, la novela de Luis y Clara y todas las narrativas que la encuadran y fragmentan, muestran los límites y peligros del imperio y el alto costo de conquistas amorosas e imperiales donde el mar parece ser una tumba sin sosiego y el amar un viaje lleno de zozobras. 


\section{Q Bibliografía}

» Allen, R. H. (1963). Star Names: Their Lore and Meaning. New York: Dover Publications.

» Álvarez Lobato, C. (2008). "Identidad y ambivalencia: una lectura de Palinuro de México desde el barroco”. Nueva Revista de Filología Hispánica, 56, 1, 123-139.

"Barnés Vázquez, A. (2009). 'Yo he leído en Virgilio': la tradición clásica en el Quijote. Vigo: Editorial Academia del Hispanismo.

» Bordas Ibáñez, C., Carrera, J.J. et al (200o). Aspectos de la cultura musical en la corte de Felipe II. Madrid: Colección Especial Caja Madrid.

» Brown, R. D. (1990). “The Homeric Background to a Vergilian Repetition”. The American Journal of Philology, 111, 182-186.

»Camamis, G. (1977). “El hondo simbolismo de la ‘hija de Agi Morato”. Cuadernos Hispanoamericanos, 319, 71-102.

»Canavaggio, J. (2005). "Los amores de don Luis y doña Clara: ¿Esbozo de novela o episodio integrado?”. Monteagudo, 10, 13-27.

"Caro Mallén de Soto, A. (1997). "El conde Partinuplés”. En: Scott Soufas, T. (ed.), Women's Acts: Plays by Women Dramatists of Spain's Golden Age. Lexington: The University of Kentucky Press, 133-162.

»Cervantes, M. de (2007). Don Quijote de la Mancha. Edición de F. Rico. Madrid: Punto de Lectura.

»Cervantes, M. de (1819). El ingenioso hidalgo don Quijote de la Mancha de Miguel de Cervantes Saavedra. Edición de V. de los Ríos. Madrid: Imprenta Real.

»Cervantes, M. de (1833). El ingenioso hidalgo don Quijote de la Mancha. Edición de D. Clemencín. 3 vols. Madrid: E. Aguado.

"Cervantes, M. de (1978). El ingenioso hidalgo don Quijote de la Mancha. Edición de L. A. Murillo. 2 vols. Madrid: Castalia.

»Connolly, C. (1981). La tumba sin sosiego. México: Premiá. Baeza, R. (trad.).

"Connolly, C. (1981). The Unquiet Grave: A World Cycle by Palinurus. New York: Persea Books.

»Cruz, A.J. (2005). “Dorotea's Revenge”. Bulletin of Hispanic Studies, 82, 615-32.

»De Armas, F. A. (2011). Don Quixote among the Sarracens: A Clash of Civilizations and Literary Genres. Toronto: University of Toronto Press.

»De Armas, F. A. (2010). “Un texto fuera de lugar: Virgilio en el Quijote”. Revue Romane, 45, 2, 191-213.

»Del Paso, F. (1977). Palinuro de México. La Habana: Casa de las Américas.

»Del Paso, F. “Premio Cervantes”. El País, 23 de abril de 2016. En: https://elpais. com/cultura/2016/o4/23/actualidad/1461411028_12108o.html

»Esquival-Heinemann, B.P. (2007). “El Quijote en la música italiana en los siglos XVIII y XIX”. En: Lolo, B. (ed.), Cervantes y el Quijote en la música: estudios sobre la recepción de un mito. Madrid: Ministerio de Educación y Ciencia/Centro de Estudios Cervantinos, 171-86. 
»Fajardo, S. (1986). “The Enchanted Return: On the Conclusion of Don Quijote, I". Journal of Modern and Renaissance Studies, 16, 233-51.

» Finello, D.L. (1994). Pastoral Themes and Forms in Cervantes' Fiction. Lewisburg: Bucknell University Press.

» Flores, R.M. (1979). “El caso del epígrafe desaparecido: capítulo 43 de la edición príncipe de la primera parte del Quijote”. Nueva Revista de Filología Hispánica, 28, 352-60.

" Flores, R. M. (1995). “¿Cómo iban a terminar los amoríos de Dorotea y don Fernando? Primera parte del Quijote". Nueva Revista de Filología Hispánica, 43.2, 455-75.

» Garcés, M.A. (2002). Cervantes in Algiers: A Captive's Tale. Nashville: Vanderbilt University Press.

» Gaylor, M. (1978-1979). “Metaphor and Fable in Góngora’s Soledad primera”. Revista Hispánica Moderna, 40, 97-112.

» Gaylor, M. (1993). “The Whole Body of Fable with All of Its Members: Cervantes, Pinciano, Freud". En: D. de Armas, Wilson y R.A. El Saffar, Anthony (eds.), Quixotic Desire: Psychoanalytic Perspectives on Cervantes. New York: Cornell University Press, 117-34.

» Góngora y Argote, L. de (1994). Soledades, Jammes, R. (ed.). Madrid: Castalia.

» Hannah, R. (2013). "The Stars of lopas and Palinurus". The American Journal of Philology, 114, 1, 123-35.

»Ibáñez Molto, M. A. (1986). "Humor surrealista en Palinuro de México”. Anales de LH, 15, $159-67$.

» Jonson, C. B. (1982). “Organic Unity in Unlikely Places: Don Quijote I, 39-41". Cervantes: Bulletin of the Cervantes Society of America, 2, 2, 133-54.

" Laguna, A.M. (2019). "Shipwrecked Na(rra)tion in Cervantes". Hispanic Review, $87,2,183-207$

»Lope de Vega, F. (1968). La Dorotea, Morby, E. S. (ed.). Berkeley: University of California Press.

»Lozano Renieblas, I. (2004). “'Mar sesgo, viento largo, estrella clara', o la metáfora de la nave de amor en el Persiles". Anales Cervantinos, 36, 299-308.

» Mancing, H. (2004). The Cervantes Encyclopedia L-Z. Vol. 2. Wesport, Ct.: Greenwood Press.

» Marasso, A. (1948). Cervantes: La invención del Quijote. Buenos Aires: Hachette.

» Martín Morán, J.M. (1990). El Quijote en ciernes: Los descuidos de Cervantes y las fases de elaboración textual. Turín: Dell'Orso.

» McGaha, M. (1980). “Cervantes and Virgil”. En: McGaha, M. (ed.), Cervantes and the Renaissance. Newark: Juan de la Cuesta, 34-50.

» Mata Induráin, C. (2007). “Los dos poemas de don Luis (Quijote I, 43) y el tema de la navegación amorosa en la poesía de Cervantes". En: Romero Muñoz, C. (ed.), Por sendas del Quijote innumerable. Madrid: Visor, 129-54

"Montaner Frutos, A. (2005). "La derrota compuesta del cautivo (Quijote XLI)". Anales Cervantinos, 37, 45-106.

»Montero Reguera, J. (1997). El Quijote y la crítica contemporánea. Alcalá de Henares: Centro de Estudios Cervantinos. 
»Padrón, R. (2007). “Against Apollo: Góngora's Soledad primera and Early Modern Spanish Imperial Cartography”. Modern Language Quarterly, 68, 3 , 363-93.

» Putnam, M. C. J. (1998). Virgil's Epic Designs: Ekphrasis in the Aeneid. New Haven: Yale University Press.

»Querol Gavaldá, M. (2005). La música en la obra de Cervantes. Alcalá de Henares: Centro de Estudios Cervantinos.

»Quint, D. (1993). Epic and Empire: Politics and Generic Form from Virgil to Milton. Princeton: Princeton University Press.

»Quint. D. (2003). Cervantes' Novel of Modern Times: A New Reading of Don Quijote. Princeton: Princeton University Press.

»Riley, E. C. (2000). Introducción al Quijote. Barcelona: Crítica.

"Rodríguez Marcos, J. (2016). "Fernando del Paso critica 'el principio de un estado totalitario' en México”. El País, 25 de abril de 2016. En: https://elpais.com/ cultura/2016/04/23/actualidad/1461406148_644804.html

" Rojcewicz, S. (2018). "Our Tears: Lacrimae rerum and Thornton Wilder”. En: Bryer, J. R., Hallett, J., Oczkowicz, E. K. (eds.), Thornton Wilder in Collaboration: Collected Dramas on his Drama and Fiction. Cambridge: Cambridge Scholars Publishing, 151-71.

» Ruiz Pérez, P. (1985). “El manierismo en la poesía de Cervantes”. Edad de Oro, 4, 165-177.

"Sánchez, A. (1991). “Don Quijote, rapsoda del romance viejo”. En: Parr, J. A. (ed.), On Cervantes: Essays on L. A. Murillo. Newark: Juan de la Cuesta, 241-62.

"Schmidt, R. (2012). "El discurso astrológico en el episodio de Grisóstomo y Marcela”. eHumanista/Cervantes, 1, 183-97.

"Soriano Fuertes, M. (1855). Historia de la música española. Vol. 2. Barcelona: Narciso Ramírez.

» Tanner, M. (1993). The Last Descendants of Aeneas. New Haven: Yale University Press.

» Tirso de Molina (1946). El Aquiles. Obras dramáticas completas, de los Ríos, B. (ed.). Vol. 1. Madrid: Aguilar, 1897-1947.

»Virgilio (2011). La Eneida. Edición y traducción de E. Gómez de Miguel y J. B. Bergua. Colección La Crítica Literaria. Madrid: Ediciones Ibéricas. 